\title{
A obrigatoriedade do ensino em Portugal: um desafio para a inclusão social
}

Resumo: A pesquisadora Ana Cabrera, doutora em História Política e Institucional Contemporânea e professora do Liceu Passos Manuel, escola central de Lisboa, fala sobre as mudanças na educação em Portugal com a obrigatoriedade de as escolas receberem a todos os jovens em idade escolar. Para a educadora, a escola tem um papel fundamental na mudança social e o desafio que se coloca para os professores é como tornar o ensino inclusivo, representando para jovens e crianças uma oportunidade real de se deslocarem de uma situação social desfavorável na qual suas famílias estão radicadas. Sua preocupação é como alcançar esses objetivos diante da aceleração das mudanças ocorridas na sociedade portuguesa nos últimos vinte anos, como a capacitação adequada de professores para essa realidade.

Palavras-chave: educação, comunicação, história, política, inclusão social.
Abstract: The researcher Ana Cabrera, PhD in Political and Institutional Contemporary History and teacher in the Liceu Passos Manuel, central school in Lisbon, talks on the changes in Portuguese Education with the teaching obligation, that forces schools to receive all youngs in school age. For the educator, school has a fundamental role in social change and the challenge presented to teachers is how to take charge of the inclusive teaching as a real opportunity for youngs and children manage to displace from the adverse social situation in which their families live. She worries on how to reach those objectives considering the acceleration of changes that occurred in Portuguese society along last 20 years and how to adequate teachers capacitation for this reality.

Keywords: education, communication, History, Politics, social inclusion.

Nas pesquisas sobre censura e democracia que venho desenvolvendo, tenho tido relações próximas com instituições portuguesas para a troca de idéias e para atividades conjuntas. A Escola de Comunicações e Artes da USP assinou convênio com a Universidade de Coimbra, do qual sou a responsável aqui no Brasil, o que tem estreitado ainda mais os laços com Portugal. Nas muitas atividades que desenvolvi nos dois últimos anos, a pesquisadora Ana Cabrera, doutora em História Política e Institucional Contemporânea, tem sido figura constante nesses encontros por seu interesse, competência e entusiasmo com os quais impregna tudo o que faz. Trata-se também de uma professora excelente que se interessa verdadeiramente pela sala de aula, por seus alunos e pela atualização da vida escolar em Portugal. Assim, aproveitei uma oportunidade de estar com ela, durante almoço no Museu Nacional do Teatro, em Lisboa, onde pudemos entrevistá-la para a revista Comunicação \& Educação. Tenho certeza de que nossos leitores irão se sentir próximos de suas idéias e opiniões. Vamos a elas então. 
C\&E: Poderia se apresentar para nossos leitores?

AC: Sou licenciada em História, mestra em Ciências da Comunicação e doutora em História Política e Institucional Contemporânea. Tenho 53 anos e, além de pesquisadora, sou também professora do $3^{\circ}$ ciclo e do ensino secundário, que é o ensino pré-universitário.

C\&E: Qual é a escola em que leciona?

AC: Estou no Liceu Passos Manuel, escola central de Lisboa, associado a uma comunidade educativa mais ampla. Recentemente foram realizados agrupamentos em Portugal e, há dois anos, nossa escola faz parte de um agrupamento com escolas do $1^{\circ}$ ciclo. Com esse arranjo, as comunidades locais de Lisboa, além de acompanhar a educação escolar dos filhos mais velhos, têm, próximo a suas residências, jardins de infância e educação pré-escolar e as escolas do $1^{\circ}$ ciclo, que são as primárias. Passos Manuel oferece o $2^{\circ}$ e o 3 o ciclos e alguns cursos técnicos.

C\&E: Quais as disciplinas que a senhora leciona?

AC: Sou professora de História, mas também de currículos alternativos criados há cerca de seis anos. São áreas disciplinares não-curriculares, como a de Projeto, a de Estudo Acompanhado e a de Formação Científica. Os alunos do $2^{\circ} \mathrm{e}$ $3^{\circ}$ ciclos as têm obrigatoriamente no seu programa e constituem complementos fundamentais à sua formação.

C\&E: Alunos de diferentes séries podem freqüentar essas disciplinas? AC: Somente alunos dos $2^{\circ}$ e $3^{\circ}$ ciclos. A área de projeto também existe no ensino secundário.

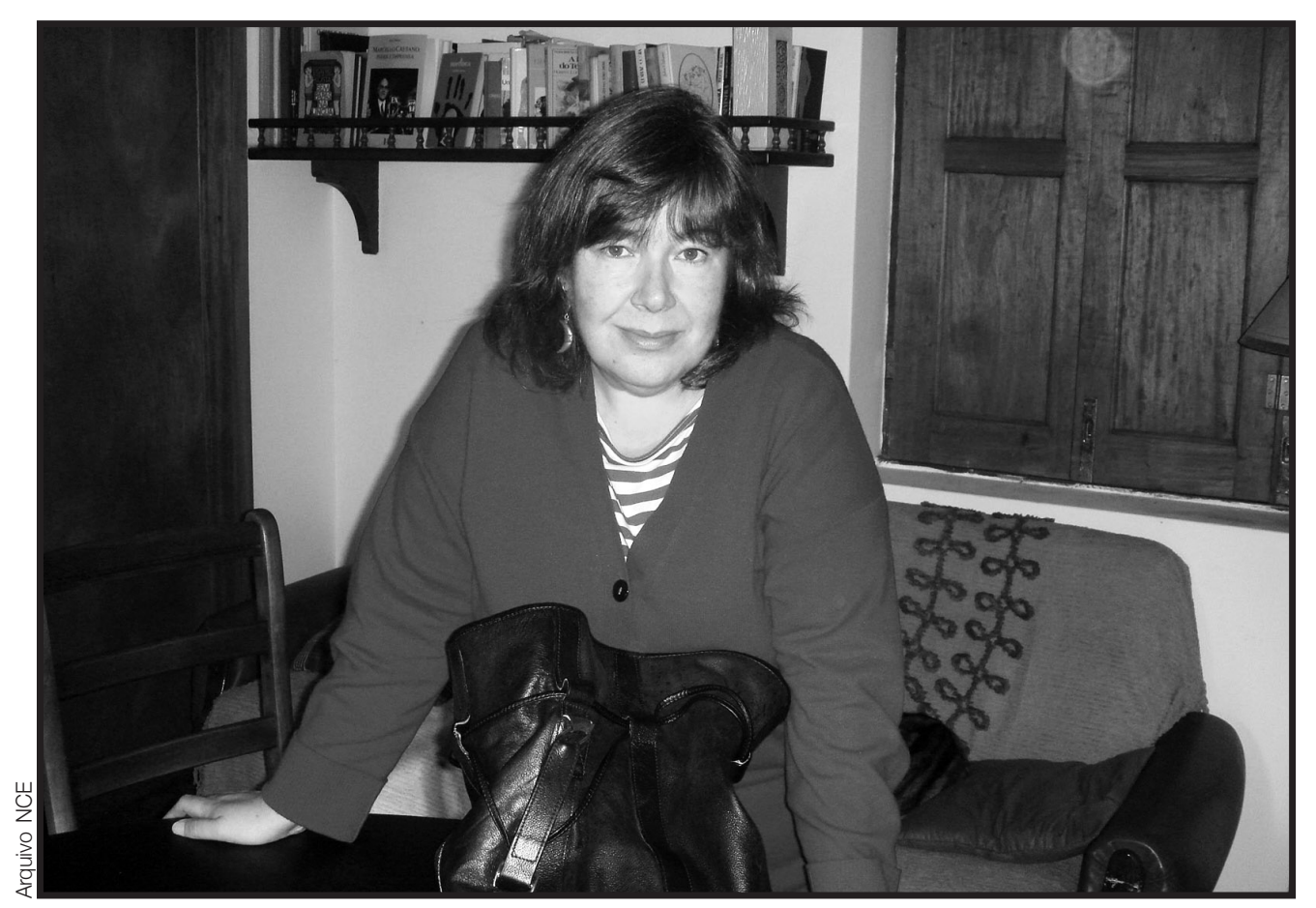


C\&E: São complementares ao estudo das disciplinas clássicas?

AC: Sim, por exemplo, na área de Estudo Acompanhado, procura-se trabalhar técnicas de estudo com as turmas: como é que se estuda, como se presta atenção. São atividades compostas de exercícios de concentração. Na área de projeto, o objetivo é para além dos conteúdos curriculares - os alunos aprendem a fazer projetos, pesquisas na internet, a organizar temas e a trabalhar fundamentalmente em grupo.

C\&E: Sua experiência é essencialmente com os jovens. Quais são os principais desafios que se colocam para o professor hoje?

AC: O principal desafio está centrado em duas situações fundamentais. Uma delas é: como motivar os alunos para aprenderem; e, a segunda, como controlar os comportamentos desviantes dentro da sala de aula. Estes são, de fato, nossos dois grandes desafios para a transmissão de conhecimento e de conteúdos científicos aos alunos, e não podem, de forma nenhuma, ser colocados em segundo lugar. Ocorre que não é possível ensinar se a turma não estiver calma, se não estiver predisposta à aprendizagem. Não há estratégia de ensino que valha se os alunos não se mostrarem motivados para aprender. $\mathrm{O}$ que nós temos neste momento em Portugal é um problema de disciplina que não é recente, mas que se transformou para nós, professores destas áreas mais centrais de Lisboa, numa dificuldade - trata-se da questão do ensino obrigatório em Portugal, que se estendeu até o 9o ano, obrigando, de fato, as escolas a receberem a todos os jovens em idade escolar. São princípios de cidadania, e se trata de uma obrigatoriedade constitucional do direito ao ensino. Antes, as escolas, sobretudo as secundárias, eram o lugar da elite. Existiam alunos bem preparados, motivados, enfim, que sabiam qual era o papel da escola e o que podiam esperar dela, e isto funcionava de uma forma mais ou menos equilibrada. Agora, com o ensino obrigatório, ainda recebemos alunos muito motivados para a escola, mas também encontramos outros que provêm de meios sociais e econômicos muito desfavorecidos. Temos, cada vez mais, crianças em instituições sociais, o que nos alerta para a desorganização da família, uma situação para a qual a sociedade e o próprio Ministério da Educação têm que dar cada vez mais respostas, pois com o ensino obrigatório este problema se tornou bem visível. Não quer dizer que esses problemas das famílias desestruturadas e desorganizadas não existissem, mas os seus filhos agora vão à escola, colocando-nos o enorme desafio de integrá-los, ensiná-los e motivá-los para a aprendizagem. São crianças muitas vezes radicadas em lares que têm uma situação de marginalidade. Este é nosso grande desafio no momento.

C\&E: Podemos dizer que há uma tendência na educação em Portugal de atender todos e promover a inclusão, seja do imigrante, seja da criança delinqüente, seja do deficiente?

AC: Essa deve ser exatamente nossa posição, não outra, porque nosso país é democrático. Somos um Estado de direito e na constituição está escrito que o ensino é obrigatório, é um direito do cidadão. Há uma questão política: a 
comunicação \& educação • Ano XIII • Número 3 • set/dez 2008

escola e o ensino têm um papel fundamental na mudança social. Sou professora porque acredito nisso e, portanto, se a escola tem esse papel, ela deve atender, receber e incluir todos. Nossa grande luta é para que o ensino seja inclusivo, abarque as situações mais marginais e que a escola possa representar uma grande mais-valia para essas crianças, como um motor para se deslocar de uma situação de marginalidade na qual sua família já está radicada. É um grande desafio.

C\&E: Os professores estão capacitados para isso?

AC: Esse é o problema. Não estão capacitados, apesar de serem pessoas competentes, mas há uma aceleração, uma mudança muito grande na sociedade portuguesa nos últimos vinte anos. Mesmo os professores que saem da universidade recentemente não têm uma formação orientada para esta realidade que é o ensino atual. Mesmo quem se encontra neste momento em formação para o ensino, não está sendo preparado para esta realidade. Isso é uma falha fundamental. As pessoas se deparam com situações constrangedoras no local de trabalho, pois não conseguem disciplinar os alunos. Como se consegue ensinar sem haver calma, paz em uma sala de aula? É evidente que existem técnicas para melhorar isso, mas há casos muito complicados. As crianças seriamente desfavorecidas têm uma imagem marginal da escola. Desejamos ser inclusivos, mas elas estão do lado de fora e não aceitam nossas regras, nossas posições, nossas lembranças, nem querem aprender aquilo que precisamos ensinar. Este é um desafio que tem o tamanho do mundo.

C\&E: Quais estratégias vêm alcançando resultado?

AC: Há resultado quando a escola conhece bem o seu público e desenvolve ações que transcendem de fato aquilo que tem sido até agora as funções e obrigações do professor. Um professor é um professor, não um assistente social. Hoje em dia, sobretudo aqueles que são diretores de turmas, precisam saber como se movimentar no mundo da assistência social, isto é, como julgar o aluno que está em uma instituição assistencial ou social? Como conhecer e como agir com o aluno que precisa de cuidados de saúde e não os têm? Como o professor ensina enfrentando esta situação? O professor deve se envolver de maneira reivindicativa, exigindo do Ministério da Educação que a escola seja dotada de assistentes sociais ou de grupos de assistentes sociais que atuem em conjunto com auxiliares da saúde local, para encaminhar os alunos com distúrbios psicológicos, emocionais ou físicos. Quando nos confrontamos com esses problemas, por mais boa vontade que o professor tenha, não existe estratégia que resolva. Se o aluno se levanta na sala de aula e está convencido de que tem ao lado uma pessoa com quem conversa, mesmo estando sozinho, pode ser um quadro de esquizofrenia; não há professor, não há estratégia adequada a este problema. Essa criança precisa permanecer na escola, estar incluída, mas paralelamente necessita ser atendida por um psiquiatra, ter um acompanhamento profissional e adquirir condições para poder aceitar o ensino. 
A obrigatoriedade do ensino em Portugal - Cristina Costa

C\&E: No ensino secundário em Portugal, qual é a preocupação com a formação de futuros universitários?

AC: Em Portugal, o ensino obrigatório, de cujos problemas venho falando, vai até a nona série. A partir daí, temos três séries - a $10^{\underline{a}}, 11^{\underline{a}}$ e $12^{\underline{a}}-$, que formam o Ensino Secundário, o qual não é obrigatório. Com relação a este último, nosso principal problema é não ser profissionalizante. Oferecemos um ensino secundário que fundamentalmente forma os alunos para a universidade, para cursos politécnicos, e essa é nossa meta.

C\&E: Como mestra em comunicação, qual é sua visão sobre a importância da comunicação no ensino atual?

AC: A comunicação é fundamental. Há pouco falávamos de quais são as grandes tendências do ensino, e estas continuam a ser, para mim, um grande desafio, que é formar na cidadania, o que é diferente de formar para a cidadania. Podemos dizer que a primeira (formar na cidadania) tem uma perspectiva um pouco mais inclusiva e significa que os alunos devem aprender a ser cidadãos exercendo a cidadania na própria escola.

C\&E: Qual é a importância da comunicação na educação?

AC: Há uma idéia comum entre os educadores de que o aluno ou o estudante deve ser agente construtor da sua aprendizagem, o que não significa diminuir, de forma nenhuma, o papel de liderança fundamental que o professor exerce na sala de aula, nem remetê-lo para uma situação secundária no que diz respeito a orientar sua matéria e explicar seu conteúdo. Deve haver sempre um momento de explanação da matéria, mesmo porque, depois, os alunos vão aplicar os conhecimentos em outros momentos e em outras situações de vida nas quais serão eles os construtores do seu saber. Deve existir aí uma grande dialética entre o momento em que o professor explica e as situações da aprendizagem propriamente ditas. Nessa circunstância, a comunicação é fundamental porque, nesses 15, 20 ou 30 minutos em que expõe a matéria, é essencial atrair os alunos para o conhecimento. É evidente que há a possibilidade de aprender boas técnicas de comunicação, mas as competências naturais de cada um são muito importantes, especialmente se nelas se incluem o domínio da boa comunicação. Imagino uma formação mais completa tanto do aluno como do professor, e para ela a comunicação é fundamental.

C\&E: Além dessa capacidade do professor, tem havido a inclusão do cinema, da televisão, do vídeo e da internet na educação?

AC: Atualmente é impossível ensinar distanciando-se de todos esses meios. Eles não são inimigos do ensino, ao contrário, são amigos da aprendizagem e, ao mesmo tempo, elementos de grande modernização do ensino. Nossos alunos do ensino obrigatório, desde o primário até o 9o ano, começam logo a trabalhar com a internet. Os trabalhos, que mencionei há pouco da Área de Projetos são pesquisas realizadas on-line. Os alunos aprendem técnicas de 
comunicação \& educação • Ano XIII • Número 3 • set/dez 2008

como utilizar os textos que pesquisam na rede e questões fundamentais com relação ao plágio, ao cuidado com as referências bibliográficas de tudo o que pesquisam, mesmo que seja um conteúdo disponível na internet. Ela é um meio fundamental e não se pode ensinar desconsiderando-a. Já a televisão foi recuperada e introduzida na prática pedagógica de que maneira? Há determinados programas e documentários televisivos que usamos nas práticas educativas. Muitas vezes os gravamos, outras os adquirimos para a escola e os aplicamos como fonte de saber. Já que não pode visitar a Grécia, o aluno é capaz de ver imagens através da televisão. Consideramos isso um grande crescimento pessoal. Os jornais também são inseridos na sala de aula porque, em muitas disciplinas, é empregado como um apontamento ou um elemento de motivação.

C\&E: Qual tem sido a postura da sua escola em relação às fraudes no uso da internet? AC: Os alunos são repreendidos, evidentemente, e, sobretudo, conscientizados de que a fraude, o plágio, são crimes contra a pessoa, isto é, contra a produção intelectual. É uma base e um objetivo educacional que impomos a nossos estudantes. Ensinamos técnicas de como se deve usar os textos e as regras de referência bibliográfica; portanto, é assim que procuramos trabalhar. Por outro lado, é verdade que a fraude existe, e mesmo no nível do ensino acadêmico.

C\&E: $O$ ensino médio em Portugal está mais voltado para as atividades técnicas ou para a pesquisa acadêmica?

AC: $\mathrm{O}$ ensino médio tem um objetivo muito claro - ele se equipara ao ensino secundário do Brasil. Estamos muito desfalcados em relação ao ensino técnico, porque desde 25 de abril, com a instauração da liberdade em Portugal, muita coisa mudou no país. Durante o Estado Novo, como era chamada a Ditadura de Antonio de Oliveira Salazar, que durou até a Revolução dos Cravos, em 1974, havia três tipos de ensino: as escolas técnicas, as escolas comerciais e as industriais e, depois, o liceu, correspondente ao ensino secundário brasileiro, que formava para a universidade. As escolas de formação para o comércio e a indústria recebiam alunos oriundos dos grupos sociais mais desfavorecidos e que buscavam o ensino comercial ou técnico. Quando ocorreu a restauração da liberdade em 25 de abril, acabou-se com este ensino que, também, não foi substituído por nenhum outro procedimento. O que passamos a oferecer a nossos alunos foi um ensino unificado, que procurava ter um componente de preparação técnica no qual os estudantes faziam os trabalhos, aprendiam alguma coisa de eletricidade, de mecânica etc. Todos os jovens eram destinados ao ensino unificado, como se designava no momento, encaminhando-se, depois, para o secundário. Aqueles que não queriam ir para o ensino secundário ficavam sem alternativa, pois o ensino só era obrigatório até o final do 2o ciclo. As pessoas que podiam estudar, continuavam; os que não podiam, procuravam um emprego. Ainda hoje não conseguimos reformular a situação de forma a oferecer, dentro do ensino secundário, alternativas profissiona- 
lizantes. As tentativas para que os alunos tivessem opções à universidade não deram bons resultados, mas sempre poderão ser revistas de maneira a proporcionar continuidade aos estudos. As reformas propostas pelo Tratado de Bolonha ${ }^{1}$ vão exatamente nesse sentido: o objetivo é sair do ensino e, em qualquer momento, poder voltar a ele e ir para a universidade. É a idéia da formação permanente.

C\&E: Qual é a relação da educação em Portugal ante o ingresso do país na comunidade européia?

AC: Todas as reformas realizadas desde que Portugal aderiu à União Européia vão no sentido de aproximar o ensino português, tanto universitário como dos outros níveis, ao ensino europeu. No nível superior, por exemplo, existe um grande intercâmbio entre as universidades, havendo mesmo redes de ensino superior técnico unindo universidades européias e até mesmo universidades dos Estados Unidos da América. Estou me referindo às escolas técnicas de nível superior e de um ensino altamente especializado, com uma abrangência mundial.

Nos outros níveis de ensino sentimos que há reformas em andamento, mas que não são devidamente explicadas aos professores. Existem alguns iluminados cientes de que essas reformas se enquadram numa nova noção dos direitos da criança, a qual obriga a olhar o ensino de uma outra maneira. Se Portugal respeita os direitos das crianças consignados internacionalmente, então o ensino português e todo quadro institucional tem que se adaptar a essa realidade. Isto é recente, porque os direitos das crianças vistos dessa maneira datam de pouco tempo, entre 1990 e 1997. Mas, no nível do ensino primário e secundário, não há, entre os educadores, um intercâmbio com a Europa. Poucos são os professores que conhecem o que se faz nos outros países, quais são as tendências educativas, quais as perspectivas para o ensino primário, para o ensino secundário, para a própria educação infantil etc. Quem é que tem esse conhecimento? Uma meia dúzia de sujeitos brilhantes - às vezes nem tanto - e que trabalham no nível do Ministério da Educação, realizam algum intercâmbio, até porque estão ligados às reformas do ensino. Mas é uma falha muito grande não envolver a comunidade educativa, de uma forma geral, neste desafio. Seria muito importante que os professores de escolas e profissionais ligados à gestão das escolas fizessem intercâmbios, visitando instituições da Comunidade Européia onde sabemos que se realizam boas práticas educativas, porque é assim que vamos aprender. Eu particularmente sinto que aí há uma enorme carência. Estou desenvolvendo um projeto para minha escola de uma investigação sobre a questão da indisciplina, que vai necessariamente desembocar na ansiedade de se aprender com os outros países, nomeadamente os países europeus, onde a questão da recepção a estrangeiros é muito mais vasta do que aqui. Temos estudantes dos países do Leste, outros que vêm da China, da África, recebemos alunos que não falam uma palavra de português. Aqui a primeira coisa é ensinar a língua, mas certos países da Europa como a França, a Inglaterra, a Alemanha, a
1. Documento conjunto assinado pelos Ministros da Educação de 29 países europeus, reunidos na cidade italiana de Bolonha, em 1999, com mudanças em relação às políticas ligadas ao ensino superior dos países envolvidos e o comprometimento em promover reformas de seus sistemas de ensino. N.E. 
comunicação \& educação • Ano XIII • Número 3 • set/dez 2008

Holanda têm uma experiência vastíssima do que fazer nessas circunstâncias e um sistema que atende a essas comunidades. Porque o ensino tem sempre esta perspectiva de inclusão e de integração das comunidades, dos jovens que vêm dos outros países da comunidade portuguesa, para que eles se adaptem bem e para que sejam úteis a si próprios e para seus desígnios. É preciso que, vindos ao nosso país, se sintam inseridos e, ao mesmo tempo, apóiem o desenvolvimento do lugar onde se considerem incluídos. Esta eu acho que deva ser a perspectiva política da proposta educacional. 